\title{
Phytosanitary Irradiation Preserves the Quality of Fresh Blueberries and Grapes during Storage
}

\author{
Jonathan Tong \\ Department of Food Science, Chapman University, 1 University Drive, \\ Orange, CA 92866
}

Cyril Rakovski

Faculty of Mathematics, Chapman University, 1 University Drive, Orange, CA 92866

\author{
Anuradha Prakash ${ }^{1}$ \\ Department of Food Science, Chapman University, 1 University Drive, \\ Orange, CA 92866
}

Additional index words. electron beam, shelf life, postharvest, sensory evaluation

\begin{abstract}
The objective of this study was to monitor the effects of irradiation on the quality of blueberries and grapes treated at phytosanitary dose levels. Blueberry varieties 'Star', 'Jewel', and 'Snowchaser' and grape varieties 'Sugraone' and 'Crimson Seedless' were irradiated at a target dose of $400 \mathrm{~Gy}$ (range of 400-590 Gy for blueberries and 400-500 Gy for grapes) and stored for 3 and 18 days under refrigeration, plus 3 days at ambient temperatures and evaluated for quality. Storage affected quality of both fruit more than irradiation treatment and there were significant differences among varieties. Irradiated 'Star' blueberries maintained their firmness and sensory scores and resisted decay. Alternatively, irradiated 'Jewel' blueberries decreased in firmness but sensory scores for overall liking were higher than the control following 3 weeks of storage. 'Snowchaser' blueberries were harvested late in the blueberry season and were not as affected by treatment or time due to their initial compromised nature. Firmness was the primary attribute affected by irradiation for both varieties of grapes, but sensory testing showed that consumers did not have a preference for control or irradiated fruit. With respect to other attributes such as color, weight loss, and soluble solids concentration (SSC)/titratable acidity (TA), there were differences among fruit varieties but treatment effects were not significant. Our results show that both, blueberries and grapes, have a high tolerance for phytosanitary irradiation and that storage affects their quality more than irradiation treatment.
\end{abstract}

Blueberries and grapes are major export crops for the United States. In 2014, the United States exported 19,524 $\mathrm{mt}$ of fresh blueberries to destinations such as Canada, Mexico, Japan, South Korea, and India (UC AIC, 2015; USDA ERS, 2015) and over $400,000 \mathrm{mt}$ of grapes mostly to Canada, southeast Asia, Mexico, China, and Australia (USDA FAS, 2015). For interstate transport of blueberries to California (CDFA, 2015) and export to certain countries, blueberries and grapes are treated to mitigate insect pests and thus allow the export of regulated produce out of quarantine areas (USDA APHIS PPQ,

Received for publication 30 July 2015. Accepted for publication 2 Sept. 2015.

This work was funded by a grant from the USDA-TASC.

We are grateful to Patty Kraikittikun for her technical contributions, and the U.S. Highbush Blueberry Council, Driscoll's ${ }^{\circledR}$, NUTEK Corporation, Veg-Fresh Farms, DLJ Produce, Fowler Packing, Top Brass Marketing, and Sodexo for their logistical assistance. ${ }^{1}$ Corresponding author. E-mail: prakash@chapman. edu.
2015). Methyl bromide is the most common phytosanitary treatment used for these fruit in the United States. It is a low cost, rapidly dispersing gas that targets a wide range of insect pests but it is in the process of being phased out because of its depleting effect on the ozone layer (US, EPA, 2013). Fumigation requires breaking the cold chain as the fruit must be fumigated at ambient temperatures, which negatively impacts product quality and shelf life. For these reasons, sulfur dioxide $\left(\mathrm{SO}_{2}\right)$ and carbon dioxide $\left(\mathrm{CO}_{2}\right)$ followed by cold treatment are now used for grapes exported to Australia (Chervin et al., 2012).

Ionizing irradiation at low doses is a promising phytosanitary treatment that is increasing in use worldwide for various fruits such as guavas, dragon fruit, rambutan, and mangoes (Kume and Todoriki, 2013). The U.S. Department of Agriculture has approved a generic dose of 400 Gy for the sterilization of all insects excluding the pupae and adults of the insect order Lepidoptera (USDA APHIS PPQ, 2015). Irradiation is effective against pests common to blueberries, such as plum curculio, Conotrachelus nenuphar (Herbst) and the blueberry maggot, Rhagoletis mendax, (Hallman and Miller, 1994) as well as grape pests such as omnivorous leaf roller (Platynota stultana), western flower thrips (Frankliniella occidentalis), spider mites, and grape mealybug (Psuedococcus maritimus).

On blueberries, irradiation appears to mostly impact firmness, but the extent is dependent on variety. 'Climax', 'Sharpblue', and 'Brightwell' blueberry varieties softened at 500 and $1000 \mathrm{~Gy}$, whereas 'Tifblue' and 'Brigatta' blueberries retained firmness (Golding et al., 2014; Miller et al., 1994, 1995; Miller and McDonald, 1996). Similar to these findings, Trigo et al. (2006) observed a dose dependent loss of firmness in 'Bonita Blue' blueberries irradiated at doses up to $3000 \mathrm{~Gy}$. Overall acceptance of the blueberries, however, was unaffected below 750 Gy. Similarly, grapes have a high tolerance to low-dose irradiation. Kim et al. (2014) found that 'Crimson Seedless' and 'Sugraone' varieties tolerated irradiation up to 800 Gy although texture of the 'Sugraone' grapes was impacted at $800 \mathrm{~Gy}$. The shelf life of two cultivars of Syrian grapes, Helwani and Baladi were improved by $50 \%$ following irradiation at 500-1000 Gy and 1500-2000 Gy, respectively (Al-Bachir, 1998).

These studies show that for both fruit, blueberries and grapes, irradiation at $400 \mathrm{~Gy}$ has little impact on quality under ideal storage temperatures. What is unknown is the effect of subsequent distribution and retail display under ambient conditions on fruit quality. Under ideal storage temperatures, the fruit may be able to tolerate the stress of irradiation and phytotoxic impacts may not be obvious, especially at the low dose of 400 Gy. However, the added stress of warm temperatures may allow irradiation-induced phytotoxic effects to manifest and have negative consequences on shelf life. For example, Sea et al. (2015) found that irradiation at 400 Gy delayed ripening in pears but that Mountain pears exhibited symptoms of irregular ripening. McDonald et al. (2012) observed development of pitting on 'Lane Late Navel' oranges treated at 200 Gy and higher during 3 weeks of refrigerated storage, which was exacerbated during 1 week at ambient temperature. Thus, this study was designed to explore the impact of storage and subsequent retail display on the quality of three varieties of blueberries and two varieties of grapes irradiated at a target dose of 400 Gy for phytosanitary purposes.

\section{Materials and Methods}

\section{Sample procurement}

Fresh southern highbush blueberries (Vaccinium darrowii), var. 'Star' (harvested in San Joaquin, CA on 4 June 2012), 'Jewel' (harvested in eastern Washington on 3 July 2012), and 'Snowchaser' (harvested in British Columbia, Canada, on 5 Sept. 2012) were provided by Driscolls ${ }^{\circledR}$ (Watsonville, CA). Blueberries were packed in $6 \mathrm{oz} / 170 \mathrm{~g}$ clamshells, 12 clamshells in a tray.

Fresh common vine grapes (Vitis vinifera and Vitis labrusca), var. 'Sugarone' (harvested 
in Shafter, CA on 26 July 2012), 'Crimson Seedless' (harvested in Fresno, CA on 11 Sept. 2012) were provided by Vignolo Farms and Fowler Packing Company, respectively. The grapes were fumigated with $\mathrm{SO}_{2}$ )and precooled in a forced-air cooler to -0.5 to $0.5^{\circ} \mathrm{C}$. About $908 \mathrm{~g}(2 \mathrm{lb})$ of grapes were then packed into perforated bags, and eight bags were placed into Styrofoam boxes $(0.60 \mathrm{~m} \times$ $0.39 \mathrm{~m} \times 0.14 \mathrm{~m})$. All fruit were transported to Nutek Corporation, Hayward, CA in a refrigerated truck $1 \mathrm{~d}$ after packing and stored at $0-1{ }^{\circ} \mathrm{C}$.

\section{Electron beam irradiation}

Cold fruit were exposed to electron beam irradiation at Nutek Corporation. The target irradiation dose level was $400 \mathrm{~Gy}$. Ten trays of each variety of blueberries and 13 cases of each grape variety were placed on their sides on racks to receive electron beam irradiation treatment. To ensure the uniformity of the dose, dose mapping was conducted on a dummy rack in the exact tray configuration before actual treatment of the experimental lot to plot the minimum and maximum dose locations. During treatment, alanine (Kodak, Rochester, NY) and radiochromic film dosimeters (GEX Corporation, Centennial, $\mathrm{CO}$ ) were placed in the upper corner of the racks to verify the dose received. Racks were conveyed at $0.203 \mathrm{~m} \cdot \mathrm{s}^{-1}$ up to a $10 \mathrm{MeV}, 8 \mathrm{~kW}$ electron beam accelerator gun (Mevex, Ottawa, Canada) and slowed to $0.018 \mathrm{~m} \cdot \mathrm{s}^{-1}$ during irradiation application. Because only one gun was used to achieve the low target dose, the racks were rotated $180^{\circ}$ and exposed for the second time to treat both sides of the trays uniformly. The blueberry cases received a minimum dose of 400 Gy and a maximum dose of 590 Gy for a dose uniformity ratio $\left(\mathrm{D}_{\max } / \mathrm{D}_{\min }\right)$ of 1.475 . The grape samples received a minimum dose of $400 \mathrm{~Gy}$ and a maximum dose of 500 Gy for a dose uniformity ratio $\left(\mathrm{D}_{\max } / \mathrm{D}_{\min }\right)$ of 1.25 . Following treatment, the fruit were transported via refrigerated truck to Chapman University where they were stored at 1 to $3{ }^{\circ} \mathrm{C}$. Temperatures were recorded during shipment and storage using temperature data loggers $\left(\log \operatorname{Tag}^{\circledR}\right.$, Auckland, New Zealand).

\section{Transport simulations}

This experiment was designed to simulate the time of ground transport to Mexico ( $3 \mathrm{~d}$ at 1 to $2{ }^{\circ} \mathrm{C}$ ) and sea transport from California to Asia, which would require $18 \mathrm{~d}$ at 1 to $2{ }^{\circ} \mathrm{C}$, followed by a 3-d period for retail display at $20{ }^{\circ} \mathrm{C}$. The quality of the fruit was assessed on arrival at Chapman University to establish baseline quality (preship) and then at 6 and 21 or $22 \mathrm{~d}$ using analytical tests and sensory evaluation.

\section{Firmness}

Fruit were removed from refrigerated storage $1 \mathrm{~h}$ before analytical testing to be brought to room temperature $\left(20^{\circ} \mathrm{C}\right)$. The force required to shear through $100 \mathrm{~g}$ of blueberries or $150 \mathrm{~g}$ of grapes was determined using a Kramer shear press with five blades (TA-91) attached to a Stable Micro
System Texture Analyzer (Model TA-XT2; Texture Technology Corporation, Scarsdale, NY and Stable Microsystems, Godalming, Surrey, UK) equipped with Exponent software. The berries were placed into the square metal container of the Kramer shear cell and a five flat-plate plunger was set at 50 or $60 \mathrm{~mm}$ for blueberries and grapes, respectively, from the bottom of the cell platform and moved downward through the blueberries at $4.0 \mathrm{~mm} \cdot \mathrm{s}^{-1}$ and upward at a posttest speed of $10.0 \mathrm{~mm} \cdot \mathrm{s}^{-1}$. The peak force in Newtons was recorded for six replicates for each treatment.

\section{Soluble solids concentration}

Fruit used for firmness analysis was juiced (Elite Gourmet Maxi-matic Juice Extractor TS-738; City of Industry, CA) and filtered through six layers of cheesecloth to obtain clear juice. Several drops of juice were placed on the prism of a digital "Pocket" Refractometer PAL (Atago Co., LTD, Tokyo, Japan) to determine percentage of SSC. Measurements were made in triplicate.

\section{Titratable acidity}

Five milliliters of fruit juice was combined with $50 \mathrm{~mL}$ of $\mathrm{CO}_{2}$-free water and titrated to $\mathrm{pH} 8.2$ (pH-200; Hannah Instruments, Woonsocket, RI) with $0.1 \mathrm{~N} \mathrm{NaOH}$. Measurements were done in triplicate for each treatment and percentage of acid was calculated using the following equation with 0.064 as the acid factor for malic acid (for blueberries) or 0.075 for tartaric acid (for grapes):

$$
\% \text { acid }=\frac{\begin{array}{c}
(\mathrm{mL} \mathrm{NaOH}) \times(0.1 \mathrm{~N} \mathrm{NaOH}) \\
\times(\text { acid factor }) \times 100
\end{array}}{\mathrm{~mL} \text { of sample }}
$$

\section{Weight loss}

The change in weight (grams) of the same three trays from the sea shipment simulation was recorded every 3 to $4 \mathrm{~d}$ to determine overall weight loss over the course of each trial. Weight measurements were taken with a SB32000 scale (Mettler Toledo, Columbus, $\mathrm{OH}$ ).

Color (grapes only). The color of the grapes was measured using the Konica Minolta Spectrophotometer CM-2500d (Konica Minolta Sensing Americas, Inc, Ramsey, NJ). Fifty berries from each treatment were selected from the middle of the cluster. The $\mathrm{L}^{*}, \mathrm{a}^{*}$, and $b^{*}$ of each berry were measured on two sides, $180^{\circ}$ from each other, for a total of 100 measurements for each treatment.

Rachis condition (grapes only). The rachis condition of four bags of grapes from each treatment was ranked using the method described by Crisosto et al. (2002). All berries were removed before analysis. A score of 1 was given to a healthy rachis, where the entire rachis including the cap stems were green. A score of 2 was given to a rachis with only cap stem browning. A score of 3 was given to a rachis with moderate browning, where the cap stems and secondary rachis displayed browning. Finally, a score of 4 was given to a rachis of severe browning, where the cap stems were brown, and there existed complete browning of the secondary and primary rachis (Crisosto et al., 2002). The overall rachis condition was determined by taking a weighted average of the scores.

\section{Sensory consumer affective testing}

All sensory testing was conducted using ASTM Committee E-18 guidelines (Chambers and Wolf, 1996; Lawless and Heymann, 2010; Stone and Sidel, 2004). About 80-100 consumers evaluated the fruit on each testing day. One hour before consumer testing, the fruit was pulled from refrigeration, brought to room temperature, rinsed with cold water, and patted dry with paper towels. Five to seven blueberries were selected at random from each treatment and placed in 2-oz plastic soufflé cups labeled with random three-digit codes. For grapes, fruit from the top secondary rachis and the bottom 76-101 mm were discarded. The clusters were washed, patted dry, and covered with plastic wrap. Consumers were given clusters of four to five berries still attached to the rachis from the remaining berries and served on paper boats labeled with unique three-digit codes.

Consumers rated the degree of liking for fruit appearance, flavor, texture, and overall liking on a 9-point hedonic scale (Peryam and Pilgrim, 1957). Tests were administered in individual booths with samples and their corresponding question sets presented in random order using SIMS 2000 Sensory Evaluation software (Berkley Heights, NJ) to prevent positional bias. Consumers were prompted to cleanse their palate with an unsalted soda cracker and filtered water between samples.

\section{Statistical analysis}

Each fruit variety was analyzed individually due to differences in age from harvest. Statistical analysis was carried out using the $\mathrm{R}$ statistical software package (R Development Core Team 2012, Vienna, Austria). Linear mixed effect models (lme4) were implemented to assess the effects of age and treatment on each of the various analytical measurements of quality as well as sensory attributes and estimate population means (Galecki and Burzykowski, 2013; McDonald et al., 2012). Random effects were used to account for the correlation induced by the repeated evaluations of each unique panelist over time. Bonferonni's procedure for multiple comparison adjustments was used to keep the overall alpha level of the multiple hypotheses testing under the nominal level of 0.05 .

\section{Results and Discussion}

\section{Firmness}

The firmness of the 'Snowchaser' blueberries was initially almost $50 \%$ lower on average compared with the 'Star' and 'Jewel' varieties (Fig. 1A). This may be related to the fact that the 'Snowchaser' blueberries were harvested close to the end of the West Coast 
season (September), and were past their quality peak on receipt.

In all three varieties of blueberries, an immediate decrease in firmness following irradiation was observed but the differences were not significant $(P>0.05)$ (Fig. 1A). For the 'Star' blueberries, irradiation decreased firmness by $\approx 10 \%$ and the control and irradiated blueberries firmness remained unchanged during storage. For 'Jewel' blueberries, treated and untreated berries continued to soften over time $(P \leq 0.05)$. For 'Snowchaser' blueberries, after the initial softening, irradiated berries maintained firmness during storage, whereas the control blueberries continued to soften over time $(P<0.05)$ such that by the end of the 3 -week storage study, the control blueberries became softer than the irradiated blueberries.

'Sugraone' grapes softened by $20 \%(P<$ $0.05)$ immediately on irradiation, and both control and treated grapes further softened by $\approx 10 \%$ during 3 weeks of storage (Fig. $1 \mathrm{~B}$ ). 'Crimson Seedless' were not impacted initially by radiation but during storage, 'Crimson' grapes declined in firmness with irradiated grapes showing greater decline in firmness $(\approx 20 \%)(P<0.05)$ than the control $(\approx 10 \%)$.

Irradiation-induced loss of firmness has been observed in many fruits (Gunes et al., 2001; Miller et al., 1994; Yu et al., 2006). Pectin components and other cellular structural materials responsible for texture are known to be sensitive to irradiation (McDonald et al., 2012; Prakash et al., 2002). Similar softening has been observed in 'Climax' and 'Sharpblue' varieties of blueberries, which exhibited a dose dependent decrease in firmness (Miller et al., 1994, 1995) with average percent of soft blueberries irradiated at 750 to 3000 Gy increasing from $26.5 \%$ to $47.5 \%$ over $14 \mathrm{~d}$ of storage (Miller et al., 1994). In contrast to blueberries, our results show that grapes seem to have a relatively high tolerance to change in texture due to irradiation treatment.

Soluble solids content. Although average SSC values differed between the three varieties of blueberries, irradiation affected only the "Jewel' variety (Table 1), reducing SSC by a small but significant amount $(P<$ 0.05 ) during storage. Similarly, 'Crimson Seedless' berries had a much higher SSC (20-21\%) than the 'Sugraone' berries (15$16^{\circ}$ Brix) but there was little change in SSC due to treatment or time (Table 1) for both berries. Sugar content is a maturity indicator during harvest and must meet at least 16.5 ${ }^{\circ}$ Brix for California grapes (Chervin et al., 2012). An increase in respiration rate can cause greater utilization of sugars and previous studies show that the effect of irradiation on SSC is dependent on the type of fruit. Cherries, apricots, and peaches irradiated up to 600 Gy had lower SSC values than the control, but SSC did not change significantly over time (Drake and Neven, 1998. In grapes, however, Paek (2014) showed no change in SSC in grapes irradiated up to $800 \mathrm{~Gy}$.

A

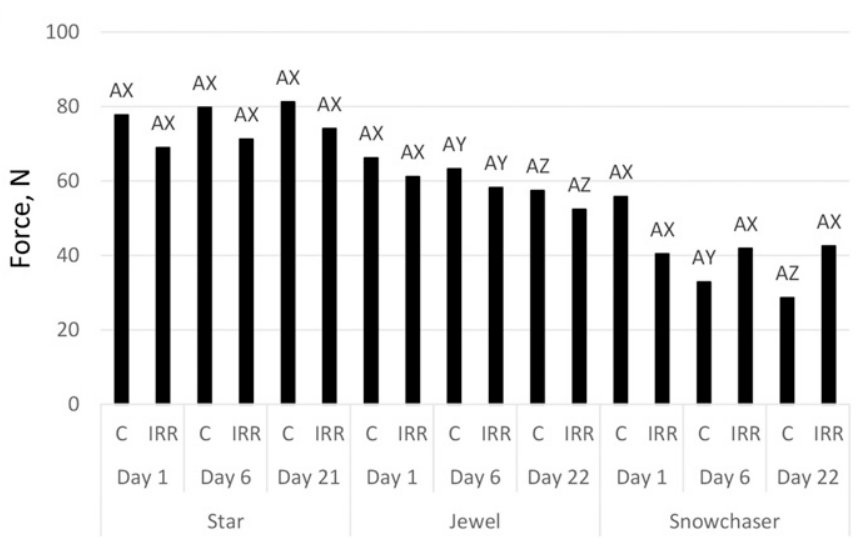

B

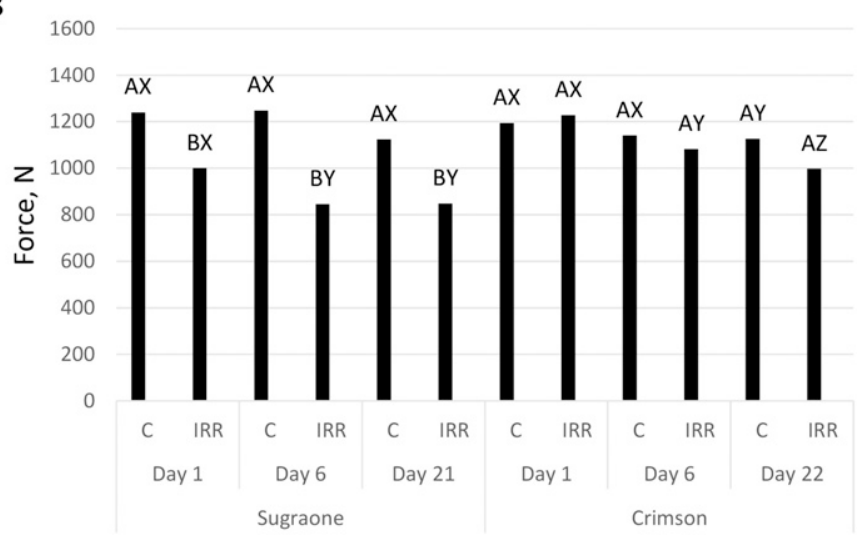

Fig. 1. Effect of irradiation and storage on the Kramer shear force of $(\mathbf{A})$ three varieties of blueberries and (B) two varieties of grapes. Within each variety, letters A and B indicate differences between treatments and letters $\mathrm{X}$ and $\mathrm{Z}$ indicate differences due to storage.

Table 1. Estimated means for titratable acidity (TA) and soluble solids content (SSC) following irradiation and storage of three varieties of blueberries and two varieties of grapes. ${ }^{2}$

\begin{tabular}{|c|c|c|c|c|c|c|c|c|c|}
\hline & \multicolumn{3}{|c|}{$\mathrm{SSC}$} & \multicolumn{3}{|c|}{ TA } & \multicolumn{3}{|c|}{ SSC:TA ratio } \\
\hline & $\overline{\text { Day } 1}$ & Day 6 & Day 21 & Day 1 & Day 6 & Day 21 & $\overline{\text { Day } 1}$ & Day 6 & Day 21 \\
\hline \multicolumn{10}{|c|}{ Blueberries 'Star' } \\
\hline Control & 12.7 & 12.7 & 12.8 & 0.64 & 0.6 & 0.56 & 19.8 & 21.2 & 22.86 \\
\hline Irradiated & 12.5 & 12.5 & 12.5 & 0.64 & 0.62 & 0.57 & 19.5 & 20.2 & 21.93 \\
\hline \multicolumn{10}{|c|}{ Blueberries 'Jewel' } \\
\hline Control & 10.6 & $10.5 \mathrm{a}$ & $10.4 \mathrm{a}$ & $0.54 \mathrm{ax}$ & 0.39 ay & $0.29 \mathrm{z}$ & 19.6 & 26.9 & 35.86 \\
\hline Irradiated & 10.2 & $10.0 \mathrm{~b}$ & $9.6 \mathrm{~b}$ & $0.48 \mathrm{bx}$ & 0.42 by & $0.34 \mathrm{z}$ & 21.3 & 23.8 & 28.24 \\
\hline \multicolumn{10}{|c|}{ Blueberries 'Snowchaser' } \\
\hline Control & 11.9 & 11.9 & 11.9 & 0.48 & 0.46 & 0.45 & 24.8 & 25.9 & 26.44 \\
\hline Irradiated & 11.6 & 11.8 & 11.9 & 0.45 & 0.43 & 0.42 & 25.8 & 27.4 & 28.33 \\
\hline \multicolumn{10}{|c|}{ 'Sugraone' grapes } \\
\hline Control & 16.3 & 16.2 & 15.9 & 0.53 & 0.54 & 0.56 & 30.9 & 30.3 & 28.58 \\
\hline Irradiated & 16.1 & 16.0 & 15.7 & 0.50 & 0.51 & 0.53 & 32.3 & 31.6 & 29.75 \\
\hline \multicolumn{10}{|c|}{ 'Crimson' grapes } \\
\hline Control & 20.5 & 20.6 & 21.2 & 0.43 & 0.42 & 0.39 & 47.4 & 48.9 & 53.96 \\
\hline Irradiated & 20.7 & 20.8 & 21.4 & 0.42 & 0.41 & 0.38 & 49.3 & 50.8 & 56.21 \\
\hline
\end{tabular}

${ }^{z}$ Values in the same row/column that are followed by the same letter are not significantly different. Letters $\mathrm{a}$ and $\mathrm{b}$ in a column represent differences between treatments on any given day. Letters $\mathrm{x}$ and $\mathrm{y}$ in rows represent differences due to storage for a given treatment.

\section{Titratable acidity}

Titratable acidity values decreased for all blueberry varieties over time (Table 1 ) but the effects of irradiation and storage were only significant for the Jewel variety of blueberries. By the end of storage, the TA of the 'Jewel' variety was reduced by almost $50 \%$. The TA of both varieties of grapes was not significantly $(P>0.05)$ affected by treatment or storage over the 3 -week period
(Table 1). Moreno et al. (2007) have reported that irradiating blueberries up to $3200 \mathrm{~Gy}$ did not change the acidity level over time, and Paek (2012) reported no difference in TA in grapes treated at dose levels up to $800 \mathrm{~Gy}$ and stored for 3 weeks.

\section{Rachis}

The rachis of treated and nontreated 'Sugraone' and 'Crimson Seedless' varieties 
browned over time, but there was no difference $(P>0.05)$ between the rachis of irradiated and nonirradiated berries on any given test day (Fig. 2). The rachis of the 'Sugraone' variety browned at a faster rate than the 'Crimson Seedless' variety. Paek (2014) found that the rachis of irradiated 'Sugraone' and Crimson Seedless grapes at 400 Gy was significantly browner than the control, but that was not observed in this study. Rachis browning was affected by the age of the berries and browning occurred at the same rate with or without irradiation. Crisosto et al. (2002) attributed stem browning to water loss that naturally occurs during postharvest handling. Temperature fluctuations can also cause severe drying and stem browning (Chervin et al., 2012).

\section{Weight loss}

There was no effect of treatment for any of the blueberry or grape varieties and during the sea shipment simulation, both fruits experienced an approximate weight loss of $3 \%$ to $4 \%$ over time (data not shown). According to Chervin et al. (2012), significant water loss occurs in grapes during the $8 \mathrm{~h}$ immediately following harvest and can range from $0.5 \%$ to $2.1 \%$. Water loss during storage is dependent on packaging, humidity, and temperature, and leads to rachis browning and loss of firmness in grapes. Similar to our results, $\approx 3 \%$ weight loss was observed in control and 500 Gy treated 'Helwani' grapes after 4 weeks of storage (Al-Bachir, 1998) and Kang et al. (2012) observed $\approx 4 \%$ weight loss in 'American Red Globe' grapes irradiated up to 1000 Gy over a period of $14 \mathrm{~d}$.

Color. The color of the 'Sugraone' berries was more affected by storage time than by irradiation treatment, with significant darkening after 3 weeks of storage $(P \leq 0.05)$ for both treatments (Table 2). A significant decrease $(P \leq 0.05)$ in $b^{*}$ values occurred after the 3-week period, suggesting a loss in yellowness. The color of 'Crimson Seedless' berries was affected by irradiation treatment $(P \leq 0.05)$, which caused a lightening effect,

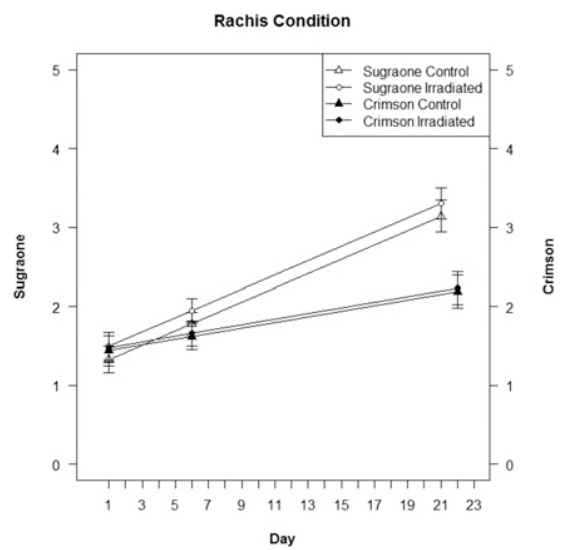

Fig. 2. Effect of irradiation and simulated transport on rachis browning of 'Sugraone' and 'Crimson' Seedless grapes. Rachis browning was measured on a 4-point scale using the method described by Crisosto et al. (2002). exhibited by a higher $L^{*}$ value (Table 3 ). There was no difference $(P>0.05)$ in a* values of the irradiated berries, but both treatments significantly $(P \leq 0.05)$ declined with time, indicating a loss in redness by the 3 rd week of storage. The $b^{*}$ values of the treated berries were significantly higher $(P \leq$ $0.05)$ than the control, which indicates that irradiation may accelerate a loss in blueness. A similar lightening effect on 'Bing' cherries treated at $600 \mathrm{~Gy}$ has been observed (Drake and Neven, 1998). Though the color profiles of the grapes, as measured by the colorimeter, changed during storage, visual differences were not discernible by the naked eye. Furthermore, consumer liking in regard to they were insensitive to changes in color and rachis browning.

\section{Consumer panels}

Table 3 shows the scores from sensory testing of blueberries and grapes. The 'Snowchaser' variety showed signs of mold within a few days of storage, thus sensory testing was not conducted for this variety of blueberries.

For the most part, consumers did not rate the control or irradiated blueberries differently. For 'Star' blueberries, there were no differences between the control and irradiated samples for consumer liking of any attribute for any of the simulations (Table 3). For 'Jewel' blueberries, consumer liking scores for overall liking, texture, and appearance of the control and irradiated blueberries decreased $(P \leq 0.05)$ over time. However, appearance did not change, indicating that

sensory scores for flavor were higher $(P<$ $0.05)$ for the irradiated berries than the control berries after storage suggesting a decline in quality of the control blueberries with time. The decline in flavor scores for the 'Jewel' blueberries coincides with the decrease in TA during storage.

The treated and nontreated grapes of both varieties scored close to 7.0 or above for all attributes on both sensory test days (Table 3 ). There were no differences $(P>0.5)$ due to treatment or storage in appearance, flavor, texture, or overall liking for either variety. Despite the storage tests ending with $2 \mathrm{~d}$ at ambient temperature, the grapes maintained high sensory scores. These results show that irradiated grapes are highly tolerant of phytosanitary irradiation and can likely withstand air and sea shipment to Australia and ground shipment to Mexico.

\section{Conclusion}

The three blueberry varieties responded differently to irradiation but the differences in responses may be related to other factors such as pre- and postharvest environmental conditions, harvest times, and duration/ distance between harvest and treatment. Their quality indicators also changed differently during storage. Similarly, the two grape varieties responded somewhat differently to irradiation treatment, but most quality attributes were affected by storage time and not irradiation treatment. Texture was the major attribute affected by irradiation for the blueberries and 'Sugraone' grapes; however, this

Table 2. Estimated means for color $\mathrm{L}$, $\mathrm{a}$, and $\mathrm{b}$ values following irradiation and storage of two varieties of grapes. $^{\mathrm{z}}$

\begin{tabular}{|c|c|c|c|c|c|c|c|c|c|}
\hline & \multicolumn{3}{|c|}{$\mathrm{L}$} & \multicolumn{3}{|c|}{$\mathrm{a}$} & \multicolumn{3}{|c|}{$\mathrm{b}$} \\
\hline & Day 1 & Day 6 & Day 21 & Day 1 & Day 6 & Day 21 & Day 1 & Day 6 & Day 21 \\
\hline \multicolumn{10}{|c|}{ 'Sugraone' grapes } \\
\hline Control & $58.08 \mathrm{x}$ & $57.51 \times$ & $55.65 \mathrm{y}$ & -5.59 & -5.63 & -5.31 & $20.08 \mathrm{x}$ & $19.51 \mathrm{x}$ & $17.93 \mathrm{y}$ \\
\hline Irradiated & $57.28 \times$ & $59.19 \mathrm{x}$ & $52.85 \mathrm{y}$ & -5.54 & -5.65 & -4.85 & $19.62 \times$ & $21.5 \mathrm{x}$ & $16.11 \mathrm{y}$ \\
\hline \multicolumn{10}{|c|}{ 'Crimson' grapes } \\
\hline Control & $36.13 \mathrm{a}$ & $37.86 \mathrm{a}$ & 38.14 & $13.71 \mathrm{x}$ & $12.74 \mathrm{x}$ & $10.66 \mathrm{y}$ & 3.69 & 5.33 & $4.03 \mathrm{a}$ \\
\hline Irradiated & $38.63 \mathrm{~b}$ & $38.35 \mathrm{~b}$ & 37.92 & $14.5 \mathrm{x}$ & $12.84 \mathrm{y}$ & $11.86 \mathrm{y}$ & 5.0 & 5.2 & $7.03 \mathrm{~b}$ \\
\hline
\end{tabular}

${ }^{z}$ Values in the same row/column that are followed by the same letter are not significantly different. Letters $\mathrm{a}$ and $\mathrm{b}$ in a column represent differences between treatments on any given day. Letters $\mathrm{x}$ and $\mathrm{y}$ in rows represent differences due to storage for a given treatment.

Table 3. Estimated means for consumer scores for overall liking, texture, appearance, and flavor of three varieties of blueberries following irradiation and simulated transport on a 9-point hedonic scale. ${ }^{\mathrm{z}}$

\begin{tabular}{|c|c|c|c|c|c|c|c|c|}
\hline & \multicolumn{2}{|c|}{ Overall liking } & \multicolumn{2}{|c|}{ Texture } & \multicolumn{2}{|c|}{ Appearance } & \multicolumn{2}{|c|}{ Flavor } \\
\hline & Day 6 & Day 22 & Day 6 & Day 22 & Day 6 & Day 22 & Day 6 & Day 22 \\
\hline \multicolumn{9}{|c|}{ Blueberries 'Star' } \\
\hline Control & 6.3 & 6.2 & 6.5 & 6.4 & 6.7 & 6.5 & 6.4 & 6.4 \\
\hline Irradiated & 6.6 & 6.6 & 6.6 & 6.8 & 6.6 & 6.3 & 6.6 & 6.6 \\
\hline \multicolumn{9}{|c|}{ Blueberries 'Jewel' } \\
\hline Control & $6.1 \mathrm{x}$ & 4.8 ay & $6.3 x$ & $5.2 \mathrm{y}$ & $7.0 \mathrm{x}$ & $6.3 \mathrm{y}$ & $6.2 \mathrm{x}$ & 5.1 ay \\
\hline Irradiated & $6.5 x$ & 5.8 by & $6.5 x$ & $5.8 \mathrm{y}$ & $7.1 \mathrm{x}$ & $6.4 \mathrm{y}$ & $6.5 x$ & 6.0 by \\
\hline \multicolumn{9}{|c|}{ 'Sugraone' grapes } \\
\hline Control & 7.2 & 7.0 & 7.3 & 7.3 & 7.2 & 7.7 & 7.2 & 6.8 \\
\hline Irradiated & 7.4 & 7.0 & 7.3 & 7.0 & 7.6 & 7.2 & 7.4 & 7.0 \\
\hline \multicolumn{9}{|c|}{ 'Crimson' grapes } \\
\hline Control & 7.6 & 7.4 & 7.5 & 7.3 & 7.3 & 6.8 & 7.6 & 7.4 \\
\hline Irradiated & 7.4 & 7.0 & 7.3 & 7.1 & 7.1 & 7.1 & 7.5 & 7.1 \\
\hline
\end{tabular}

${ }^{z}$ Values in the same row/column that are followed by the same letter are not significantly different. Letters $\mathrm{a}$ and $\mathrm{b}$ in a column represent differences between treatments on any given day. Letters $\mathrm{x}$ and $\mathrm{y}$ in rows represent differences due to storage for a given treatment. 
effect was not reflected in consumer liking scores. Affective tests showed that consumer acceptability was similar to the nontreated fruit even after 3 weeks of refrigerated storage and $3 \mathrm{~d}$ at ambient temperatures. Irradiation at a target dose of 400 Gy appears to be sufficiently low so that the fruit is not stressed even after exposure to ambient temperatures. These results show that in terms of quality, irradiation at $400 \mathrm{~Gy}$ to achieve the necessary quarantine for export can maintain blueberry and table grape quality to meet transportation, distribution, and storage needs for overseas markets. If irradiation is used as a quarantine treatment, the particular variety should be chosen based on its radiotolerance.

\section{Literature Cited}

Al-Bachir, M. 1998. Effect of gamma irradiation on storability of two cultivars of Syrian grapes (Vitis vinifera). Radiat. Phys. Chem. 55:81-85.

California Department of Food and Agriculture (CDFA). 2015. Summaries of exterior quarantines. 30 Aug. $2015<$ http://www.cdfa.ca.gov/plant>.

Chambers, E.C. and M.B. Wolf. 1996. Sensory testing methods. ASTM International, West Conshohocken, PA.

Chervin, C., J. Aked, and C.H. Crisosto. 2012. Grapes, p. 187-211. In: D. Reas, G. Farrel, and J. Orchard (eds.) Crop post-harvest: Science and technology. Blackwell Publishing Ltd, Hoboken, NJ.

Crisosto, C.H., D. Garner, and G. Crisosto. 2002. Carbon dioxide-enriched atmospheres during cold storage limit losses from Botrytis but accelerate rachis browning of 'Redglobe' table grapes. Postharvest Biol. Technol. 26:181-189.

Drake, S.R. and L.G. Neven. 1998. Irradiation as an alternative to methyl bromide for quarantine treatment of stone fruits. J. Food Qual. 21(6):529538.

Galecki, A. and T. Burzykowski. 2013. Linear mixed-effects models using R: A step-by-step approach. Springer, New York, NY.

Golding, J.B., B.L. Blades, S. Satyan, A.J. Jessup, L.J. Spohr, A.M. Harris, C. Banos, and J.B. Davies. 2014. Low does gamma irradiation does not affect the quality, proximate or nutritional profile of 'Brigitta' blueberry and 'Maravilla' raspberry fruit. Postharvest Biol. Technol. 96: 49-52.

Gunes, G., J.H. Hotchkiss, and C.B. Watkins. 2001. Effects of gamma irradiation on the texture of minimally processed apple slices. J. Food Sci. 66(1):63-67.

Hallman, G.J. and W.R. Miller. 1994. Irradiation as an alternative to methyl bromide quarantine treatment for plum curculio in blueberries. 1994 International conference on Methyl Bromide Alternatives and Emission Reductions, Kissimmee, FL. United States Department of Agriculture-Environmental Protection Agency, Washington, DC. p. 13-16. <https://mbao.org/ static/docs/confs/1994-orlando/papers/087.pdf>.

Kang, F., G.J. Hallman, Y. Wei, F. Zhang, and Z. Li. 2012. Effect of X-ray irradiation on the physical and chemical quality of American red globe grape. Afr. J. Biotechnol. 11(31):79667972.

Kim, C.G., C. Rakowski, F. Caporaso, and A. Prakash. 2014. Low-dose irradiation can be used as a phytosanitary treatment for fresh table grapes. J. Food Sci. 79(1):S81-S91.

Kume, T. and S. Todoriki. 2013. Food irradiation in Asia, the European Union, and the United States: A status update. Radioisotopes 62(5):291-299.

Lawless, H.T. and H. Heymann. 2010. Sensory evaluation of food: Principles and practices. 2nd ed. Springer, New York, NY.

McDonald, H., M. McCulloch, F. Caporaso, I. Winborne, M. Oubichon, C. Rakovski, and A. Prakash. 2012. Commercial scale irradiation for insect disinfestation preserves peach quality. Radiat. Phys. Chem. 81(6):697-704.

Miller, W.R., R.E. McDonald, T.G. McCollum, and B.J. Smittle. 1994. Quality of 'climax' blueberries after low dosage electron beam irradiation. J. Food Qual. 17(1):71-79.

Miller, W.R., R.E. McDonald, and B.J. Smittle. 1995. Quality of 'Sharpblue' blueberries after electron beam irradiation. HortScience 30:306308.

Miller, W.R. and R.E. McDonald. 1996. Quality of 'Brightwell' and "Tifblue" blueberries after gamma irradiation for quarantine treatment. HortScience 31:1234.

Moreno, M.A., M.E. Castell-Perez, C. Gomes, P.F. Da Silva, and R.G. Moreira. 2007. Quality of electron beam irradiation of blueberries (Vaccinium corymbosum L.) at medium dose levels (1.0-3.2
kGy). Food Sci. Technol. LEB 40(7):11231132.

Peryam, D.R. and F.J. Pilgrim. 1957. Hedonic scale method of measuring food preferences. Food Technol. 11:9-14.

Prakash, A., J. Manley, S. DeCosta, F. Caporaso, and D. Foley. 2002. The effects of gamma irradiation on the microbiological, physical and sensory qualities of diced tomatoes. Radiat. Phys. Chem. 63:387-390.

Sea, S., C. Rakovski, and A. Prakash. 2015. Ripening quality of 'Bartlett' pears (Pyrus communis L.) subjected to phytosanitary $\mathrm{x}$-ray irradiation treatment followed by simulated retail display. HortScience 50:279-287.

Stone, H. and J. Sidel. 2004. Sensory Evaluation Practices. 3rd ed. Elsevier Academic, San Diego, CA.

Trigo, M.J., M.B. Sousa, M.M. Sapata, A. Ferreira, T. Curado, L. Andrada, E.S. Ferreira, C. Antunes, M.P. Horta, A.R. Pereira, M.L. Botelho, and G. Veloso. 2006. Quality of gamma irradiated blueberries. Acta Hort. 715:573-578.

U.S. Department of Agriculture, Animal and Plant Health Inspection Service, Plant Protection and Quarantine (USDA APHIS PPQ). 2015. Treatment manual. Import and export electronic manuals. 30 Aug. 2015. <http://www.aphis. usda.gov/import_export/plants/manuals/online_ manuals.shtml $>$.

U.S. Department of Agriculture Economic Research Service (USDA ERS). 15. Fruit and tree nut data. 10 May 2015. <http://www.ers.usda. gov/data-products/fruit-and-tree-nut-data/databy-commodity.aspx>.

U.S. Environmental Protection Agency (US EPA). 2013. The phaseout of methyl bromide. $23 \mathrm{Apr}$. 2013. <http://www.epa.gov/ozone/mbr/>.

U.S. Department of Agriculture Foreign Agriculture Service (USDA FAS). 2015. Production, supply, and distribution online. 10 May 2015. $<$ https://apps.fas.usda.gov/psdonline/>.

University of California Agricultural Issues Center (UC AIC). 2015. Estimating California's agricultural exports. 10 May 2015. <http://aic. ucdavis.edu/pub/exports.html $>$.

Yu, L., C.A. Reitmeier, and M.H. Love. 2006. Strawberry texture and pectin content as affected by electron beam irradiation. J. Food Sci. 61(4):844-846. 